\title{
Characterization of jute and glass fiber reinforced polyester based hybrid composite
}

\author{
M. R. Hassan', M. A. Gafur ${ }^{2}$, A. A. Rana ${ }^{1}$, M. R. Qadir' ${ }^{2}$, S. M. Masum ${ }^{1}$, \\ A. M. Sarwaruddin Chowdhury ${ }^{1}$ and M. M. Karim ${ }^{1 *}$ \\ ${ }^{1}$ Department of Applied Chemistry and Chemical Engineering, University of Dhaka, Dhaka, Bangladesh \\ ${ }^{2} P P \&$ PDC, Bangladesh Council of Scientific and Industrial Research (BCSIR), Dhaka, Bangladesh
}

\begin{abstract}
In this research work an attempt is made to fabricate a hybrid composite material with hessian cloth (natural fiber) and glass fiber (synthetic fiber) in polyester matrix using hand lay-up process and testing was performed by ASTM standards. Main objective of this research work is to investigate the effects of use of natural fiber in the composite material with the synthetic fiber. Experimental results revealed that hybridization of composite with natural and synthetic fibers shows promising tensile strength, flexural strength and hardness. Among the hybrid composites one with the composition of three layers of glass fibers and two layers of hessian cloth (jute fiber) showed highest tensile strength and flexural strength which were found 104.63 MPa and 134.65 MPa respectively. Water absorption was high in composites having higher hessian cloth content than glass fiber. Composite with high glass fiber content showed high hardness which was 39.9 HV.
\end{abstract}

Keywords: Polyester; Jute and glass fiber; Tensile strength; Flexural strength; Hardness

\section{Introduction}

Natural fibers have already been used for the first time 3000 years ago in composite systems in the ancient Egypt, where straw and clay were mixed together to build walls. Over the last decade, polymer composites reinforced with natural fibers have received ever increasing attention, both from the academic world and from various industries. Not only that synthetic fiber reinforced composites also been used for several applications in this period, carbon fiber reinforced composite was a revolutionary material. The development of composite materials and their related design and manufacturing technologies is one of the most important advances in the history of materials. Composites are the material used in various fields having exclusive mechanical and physical properties and are developed for particular application. The combined properties of composites like resilience, creep resistance, high strength, stiffness to weight ratios, corrosion resistance, and good damping properties are the reason behind the extensive use of composites in the industries of aerospace structures, automotive parts and marine structures
(Chandra et al., 1999; Haldar et al., 2011; Sing et al., 2012 and Rana et al., 2015). Many authors have worked with polymer composite and their studies showed that low cost natural fiber can be used to reinforce composite material which is light weight and shows high strength and dielectric properties (Dhal and Mishra, 2013). On the other hand properties of composite which are reinforced with synthetic fiber are also studied by the researchers. The study revealed that usually this kind of composites show good hardness and low water absorption properties. They also show high strength, stiffness and toughness (Kusmono and Ishak, 2013). Composites made of the same reinforcing material system may not give better results as it undergoes different loading conditions during the service life. In order to solve this problem hybrid composites are the best solution for such applications. The incorporation of several different types of fibers into a single matrix has led to the development of hybrid composites. The behavior of hybrid composites is a weighed sum of the individual components in which there is a more 
favorable balance between the inherent advantages and disadvantages. A hybrid composite contains two or more types of fiber, the advantages of one type of fiber could complement with what are lacking in the other. As a consequence, a balance in cost and performance can be achieved through proper material design. Many researchers studied the properties of hybrid composites and the study showed that the hybrid composite add advantages of weight saving, cost savings, better water absorption, increased strength, and many more (Bleat and Humberstone, 1999; Venkateshwaran et al., 2004; Bindal et al., 2013). Some studies were specifically concentrated on the hybrid composites made of jute fiber and glass fiber. One study of this kind of hybrid composite found that fiber lengths can interfere with the mechanical properties of the composite (Muthuvel et al., 2013). Another study showed that the outer layer containing jute layer show low strength properties than those composed of glass layer at their outer layer (Velu and Srinivasan, 2015). Some researcher also used filler in their composites and found some fillers increase tensile strength and some increases impact strength (DeshPande and Rangaswamy, 2014). This composites were also studied for the application in auto mobile industry, one study revealed that in recent times the use of steel in suspension spring is replaced by e-glass epoxy based composite and now study is going on to see the potency of hybrid composite made of e-glass, jute and epoxy as a material to build the suspension springs (Srivastava and Choudhary, 2013). For the synthesis of composite there are many techniques available in industries such as compression molding, vacuum molding, pultruding, hand lay-up and resin transfer molding. Out of all the hand lay-up process is most popular technique because it is a simple and easy method to follow to fabricate composite (Davim et al., 2014). The hand lay-up technique facilitates fabrication of very large and complex composite with minimum manufacture time. It requires simple equipment and tools which are relatively less expensive than other manufacturing processes. To the best of our knowledge, the development of glass/jute fibers reinforced polyester compositeis studied by very few authors. However, the effect of contents of different percentage of fibers on various mechanical and thermal properties was not found in the literature. In this present work natural fiber reinforced composite, synthetic fiber composite, and hybrid composite were fabricated using hand lay-up technique with same polymer matrix to the reinforcement ratio. Composites were compared by observing the effect of natural fibre reinforcement on glass fibre reinforced composite. Mechanical properties were also analyzed. All the tests were conducted as per ASTM procedures.

\section{Materials and methods}

\section{Materials}

The raw materials used in this research work were hessian cloth (jute fiber), glass fiber sheet, U-polyester resin, methyl ethyl ketone peroxide (MEKP), styrene monomers, and silica powder. Hessian cloth made from the jute fiber was used in the composite fabrication. Glass fiber fabric of $0.25 \mathrm{~mm}$ thickness and Hessian cloth of jute fiber of $0.3 \mathrm{~mm}$ thickness were given from the pilot plant and process development centre of Bangladesh council of scientific and industrial research (PP-PDC, BCSIR). The composition of glass fiber was $\mathrm{SiO}_{2} 54 \%, \mathrm{Al}_{2} \mathrm{O}_{3} 14.5 \%, \mathrm{~B}_{2} \mathrm{O}_{3} 10 \%, \mathrm{CaO} 16.5 \%, \mathrm{MgO}$ $4 \%$ and others $1 \%$. U-polyester resin, MEKP and styrene monomer were collected from the local market or more specifically from Naseem Plastic Corp. Bangladesh who imports these chemicals in Bangladesh for industrial purposes. $40 \%$ fiber was used in this investigation.

\section{Composite fabrication procedure}

All the specimens of composites in this work were fabricated using hand lay-up process of composite manufacturing. The major instruments and apparatus used for the fabrication of the composites were Paul-Otto Weber Presser Hydraulic press, Digital Balance, Open molds and Vacuum Oven (Memmert VO200cool). Hessian cloth was dried in the oven at $57-60^{\circ} \mathrm{C}$ temperature overnight for moisture removal from the cloth. Hessian cloth and glass fiber sheet were cut down to the desired size which were 6 inch $\times 6$ inch sheets with the help of scissors. The composites were made with the fiber percentage of $40 \%$. All materials used in the synthesis were weighed by the digital balance. Polymer matrix was 
made with the composition of U-polyester resin $87 \%$, styrene monomer $12 \%$, and MEKP $1 \%$. Weighed U-polyester resin, styrene monomer and MEKP were mixed in a plastic cup by stirring with a stainless steel stirrer. Mullet paper was taken, on the mullet paper one fiber sheet was placed and then the polymer resin was applied on it. After that another fiber sheet was applied on the previous one. Process went on as five layers of fiber are sandwiched together with the polymer resin. Then the sandwiched composite was placed into the open mold. The mold was then inserted to the Paul-Otto Weber Presser Hydraulic press machine. The machine was set at $100 \mathrm{KN}$ pressure applied on to the composite for 6 hours as curing took place. After that open mold was ejected from the Paul-Otto Weber Presser Hydraulic press machine and the cured composite was taken out from the mold.

\section{Experimental procedure}

All the characterization tests were performed at Pilot Plant and Process Development Center of Bangladesh Council of Scientific and Industrial Research.Tensile strength tests of the composites were carried out according to the test procedure ASTM D638 on Universal Testing Machine (Hounsfield UTM10KN H10KS). The specimens were placed in the grips and were pulled at a speed of $2 \mathrm{~mm} / \mathrm{min}$ until failure occurred. An extensometer is used to determine elongation and tensile modulus.Flexural tests of the composite were also carried out on the Universal Testing Machine (Hounsfield UTM10KN H10KS) by following the procedure ASTM D790 3 point loading. The specimen was placed on two supports and load was applied at the center.Water absorption test were carried out according to ASTM D570 procedure. Samples were dried for $24 \mathrm{hr}$ in oven, cooled and then weighed. The oven-dried samples were immersed in water for 24 hours at room temperature and then dried before weight measurement. Then the samples were regularly weighed at 48, 72, 96, 120, 144, 168, 192 hours respectively.Micro hardness test of the composites were carried out on Shimadzu micro-hardness tester HMV-2series. The test load was set at $245.2 \mathrm{mN}$ (HV0.025). Thermal properties of the composites were determined by Shimadzu TG/DTA 630. All the experimental tests were repeated five times so that accu- rate result can be obtained.

\section{Results and discussion}

\section{Tensile strength}

The experimental results of tensile strength of the composites of different compositions are given in the Table I and the comparisons among the composites are shown in the Figure 1. The results show that the composite of only synthetic fiber reinforcement has high tensile strength while the composite of only natural fiber reinforcement has low tensile strength, which was quite expected. The result also indicates that addition on synthetic fiber content in natural fiber increases tensile strength. The hybrid composite 'C4' with the composition of 3 layers of glass fiber and 2 layers of hessian cloth (jute fiber) showed the highest tensile strength among the hybrid composites. The difference in tensile strength between natural fiber reinforced composite and hybrid composite is significant. In C4, glass fibers are on the exterior side which gives this particular composite a high tensile strength. 2 layers of jute fiber in $\mathrm{C} 4$ support the other 3 layers of glass fibers and tensile strength increases from $\mathrm{C} 3$ by $40.6 \mathrm{MPa}$ (Dalbehera and Acharya, 2014). On the other hand C5 shows lesser tensile strength than $\mathrm{C} 4$ whereas synthetic fiber content is higher than natural fiber content. So just one layer of jute fiber could not able to support the other layers of glass fiber and thus results in decrease of tensile strength. For all other hybrid composites there has been a certain growth in tensile strength with increase of synthetic fiber content because brittleness decreases with decrease of jute fiber content. The results indicate a good interfacial bond occurred between fibers and matrix as the tensile strengths are in the higher regions.

Table I. Results of tensile testing of the composites (G: Glass fiber, J: Jute fiber)

\begin{tabular}{cccc}
\hline $\begin{array}{c}\text { Sample } \\
\text { Name }\end{array}$ & $\begin{array}{c}\text { Fiber } \\
\text { orientation }\end{array}$ & $\begin{array}{c}\text { Tensile Strength } \\
(\mathrm{MPa})\end{array}$ & $\begin{array}{c}\text { Standard } \\
\text { Deviation }\end{array}$ \\
\hline C1 & JJJJ & 38.6875 & 3.219 \\
C2 & JJGJJ & 59.375 & 5.288 \\
C3 & JGJGJ & 64.025 & 10.59 \\
C4 & GJGJG & 104.625 & 4.43 \\
C5 & GGJGG & 92.1 & 3.470 \\
C6 & GGGGG & 106.8 & 7.021 \\
\hline
\end{tabular}




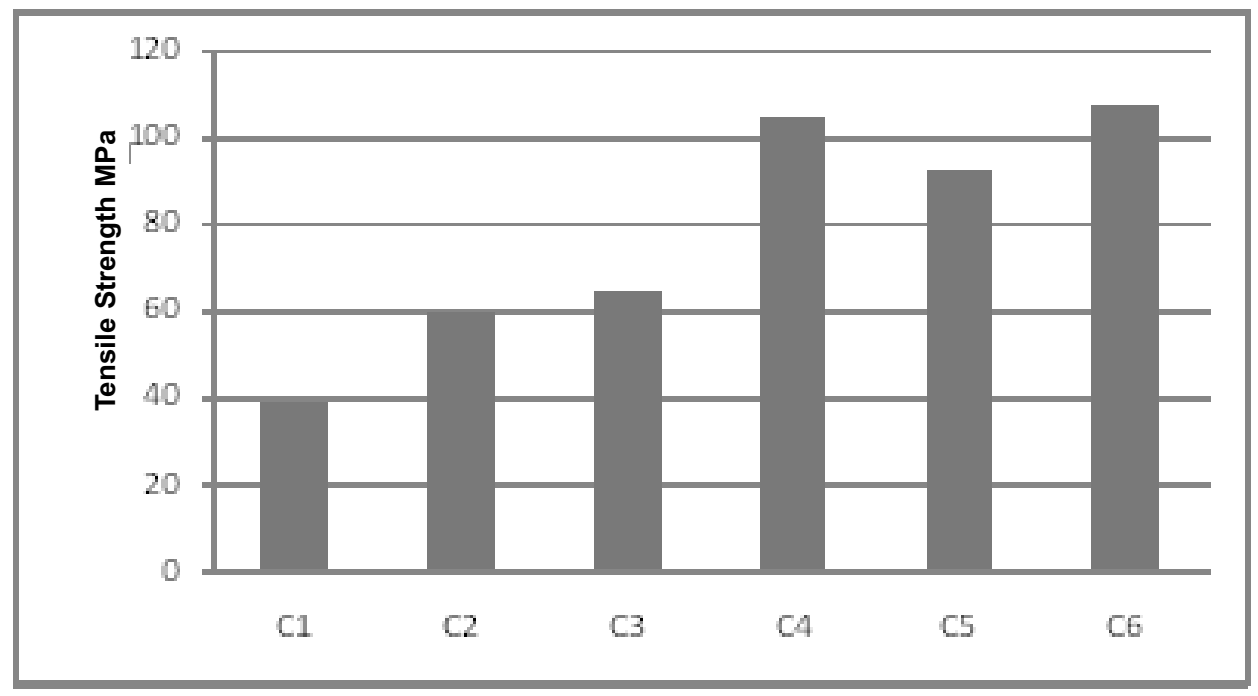

Fig. 1. Comparison of tensile strengths of the composites

\section{Flexural Strength}

Flexural test results of the composites are given in the Table II and comparisons among the composites have been shown in the Figure 2. All the composites showed good flexural strength, both natural fiber reinforced and synthetic fiber reinforced composites. C4 shows good flexural strength than all the hybrid composites, 2 layers of jute fibers complimented 3 layers of glass fibers in a way that the stiffness of the fiber distributed finely. Just one layer increase of glass fiber in jute fiber content increased flexural strength from $85.55 \mathrm{MPa}$ to $134.65 \mathrm{MPa}$. Hessian cloth (jute fiber) reinforced composite shows lesser flexural strength than glass fiber reinforced composite because of the stiffness of the glass fiber. Due to some voids C5 gives a little low flexural strength than the previous one C4 (Dalbehera and Acharya, 2014).

Table II. Results of flexural testing of the composites (G: Glass fiber, J: Jute fiber)

\begin{tabular}{cccc}
\hline $\begin{array}{c}\text { Sample } \\
\text { Name }\end{array}$ & $\begin{array}{c}\text { Fiber } \\
\text { orientation }\end{array}$ & $\begin{array}{c}\text { Flexural } \\
\text { Strength }(\mathrm{MPa})\end{array}$ & $\begin{array}{c}\text { Standard } \\
\text { Deviation }\end{array}$ \\
\hline C1 & JJJJJ & 54.71 & 8.59 \\
C2 & JJGJJ & 80.4 & 1.8 \\
C3 & JGJGJ & 85.5 & 5.2 \\
C4 & GJGJG & 134.65 & 3.25 \\
C5 & GGJGG & 125.95 & 7.68 \\
C6 & GGGGG & 176.8 & 5.56 \\
\hline
\end{tabular}

\section{Water absorption}

The results of the water absorption test of the composites are shown in the Table III and time dependent water absorption has also been shown in the Figure 3. The results show that the water absorption is high in the composites having higher jute fiber (hessian cloth) loading over glass fiber loading.

Thus the high percentage of water absorption occurred in the composite $\mathrm{C} 1, \mathrm{C} 2$ and $\mathrm{C} 3$. As the jute fiber loading decreased the water absorption also decreased. The water absorption is low in $\mathrm{C} 4, \mathrm{C} 5$, and C6. It is because jute is capable of absorbing water and on the other hand glass fibers do not absorb water as like jute fiber. Water absorption occurs because of the small pores present in the surface of the polymer matrix through which water enters into the composite. Almost same amount of water enters into the composites but the absorption depends on the fiber nature. And this

Table III. Water absorption results of the composites (G: Glass fiber, J: Jute fiber)

\begin{tabular}{ccccccc}
\hline Sample & Fiber orien- & \multicolumn{5}{c}{ Water Absorption \% } \\
\cline { 3 - 7 } Name & tation & 24 & 96 & 120 & 168 & 192 \\
\hline C1 & JJJJJ & 7.43 & 7.53 & 7.69 & 7.70 & 7.71 \\
C2 & JJGJJ & 6.26 & 6.55 & 6.71 & 6.75 & 6.75 \\
C3 & JGJGJ & 5.58 & 5.74 & 5.76 & 5.80 & 5.81 \\
C4 & GJGJG & 4.41 & 4.88 & 4.96 & 4.98 & 4.98 \\
C5 & GGJGG & 3.39 & 3.72 & 3.76 & 3.77 & 3.78 \\
C6 & GGGGG & 2.10 & 2.32 & 2.39 & 2.39 & 2.39 \\
\hline
\end{tabular}




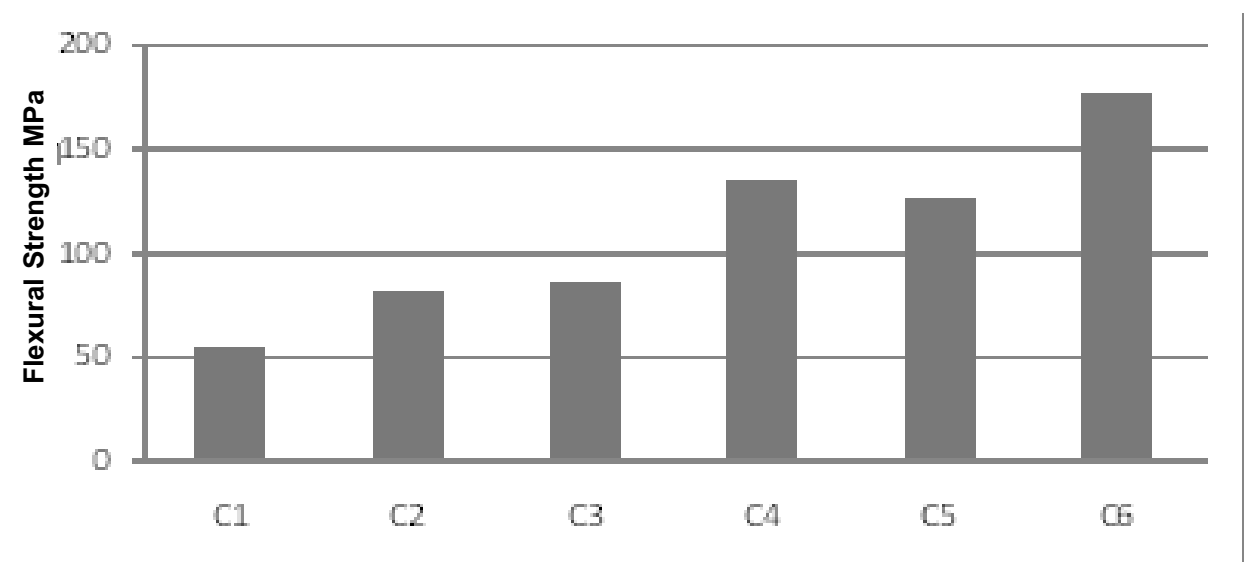

Fig. 2. Comparison of flexural strengths of the composites

is why composites of higher natural fiber content absorb water easily.

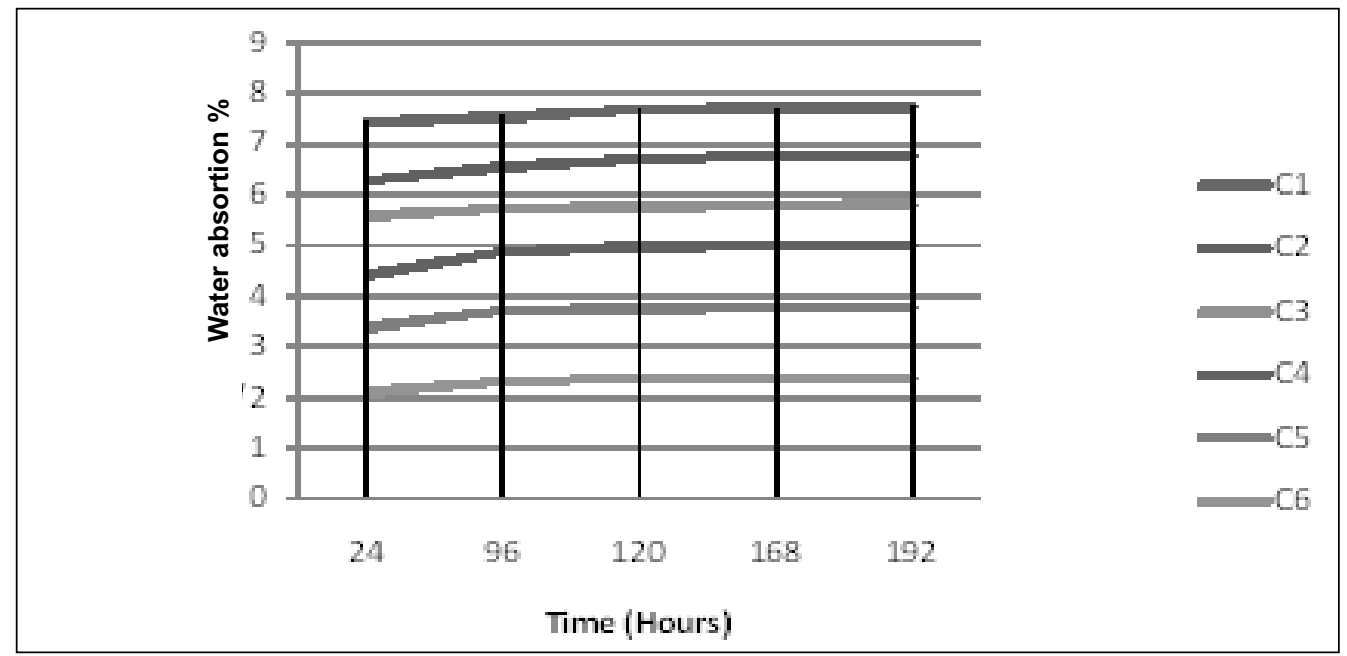

Fig. 3. Water absorption curve of the composites

\section{Hardness}

Hardness is a surface measurement since the indenter evaluates mainly the first few fiber layers next to the surface. The basic principle of micro hardness test is to see the resistance of the material from the plastic deformation caused by the indenter of the micro hardness tester. The test load was set at $245.2 \mathrm{mN}$ (HV0.025). The Figure 4 and Table IV show that
Table I. Results of micro hardness testing of the composites (G: Glass fiber, J: Jute fiber)

\begin{tabular}{cccc}
\hline $\begin{array}{c}\text { Sample } \\
\text { Name }\end{array}$ & $\begin{array}{c}\text { Fiber } \\
\text { orientation }\end{array}$ & Hardness HV & $\begin{array}{c}\text { Standard } \\
\text { Deviation }\end{array}$ \\
\hline C1 & JJJJJ & 13.0 & 1.68 \\
C2 & JJGJJ & 20.8 & 1.89 \\
C3 & JGJGJ & 27.7 & 1.85 \\
C4 & GJGJG & 32.2 & 2.06 \\
C5 & GGJGG & 34.5 & 1.9 \\
C6 & GGGGG & 39.9 & 2.12 \\
\hline
\end{tabular}




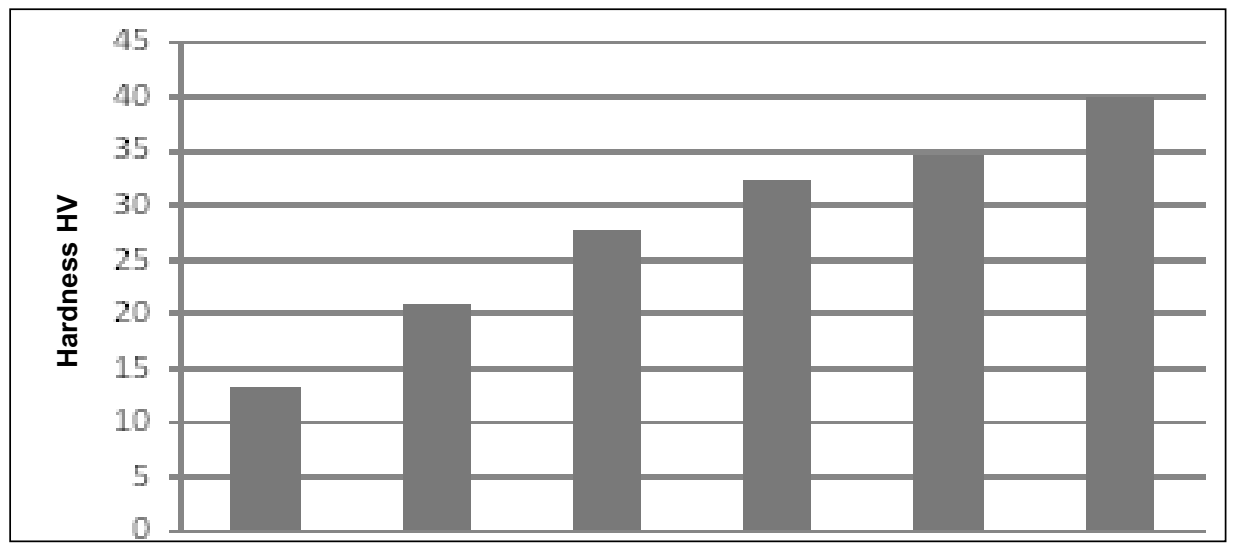

Fig. 4. Comparison of Hardness of the composites

Thermal analysis

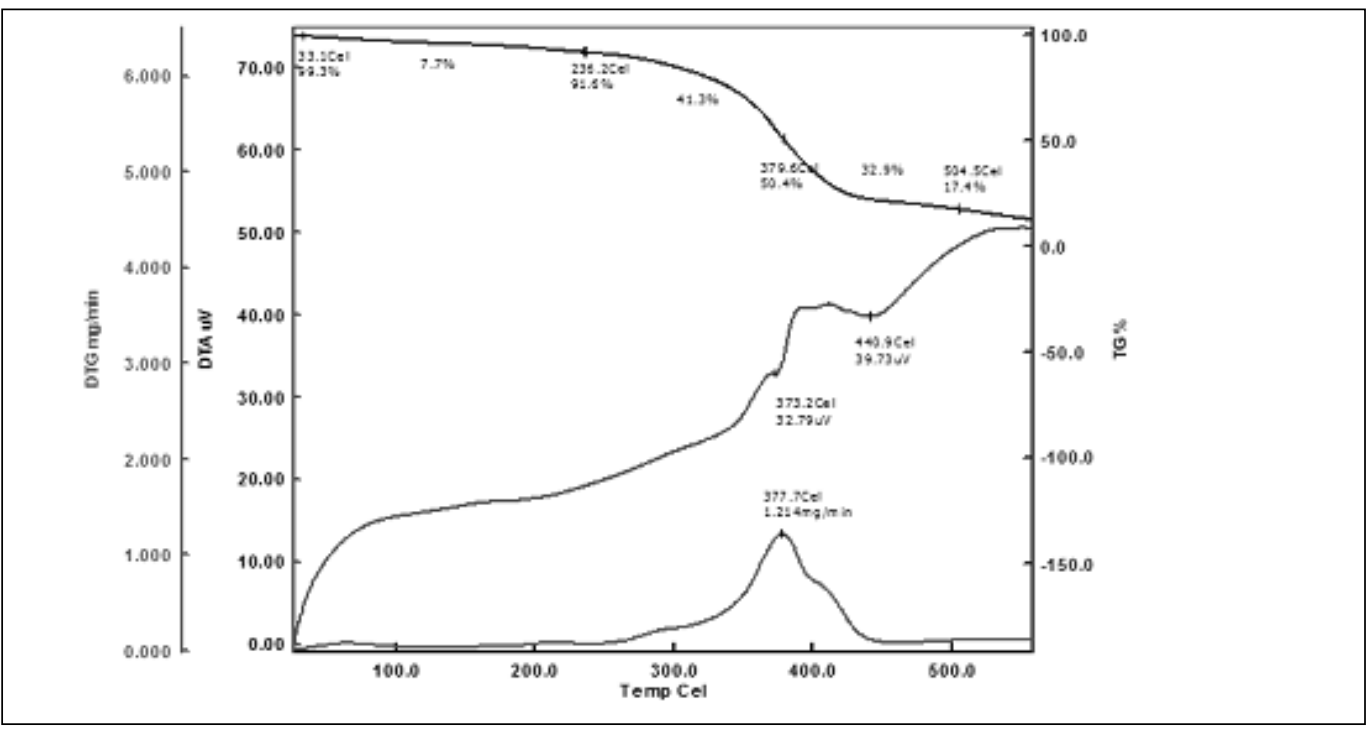

Fig. 5. TG, DTG and DTA of Composite C1(=JJJJJ)

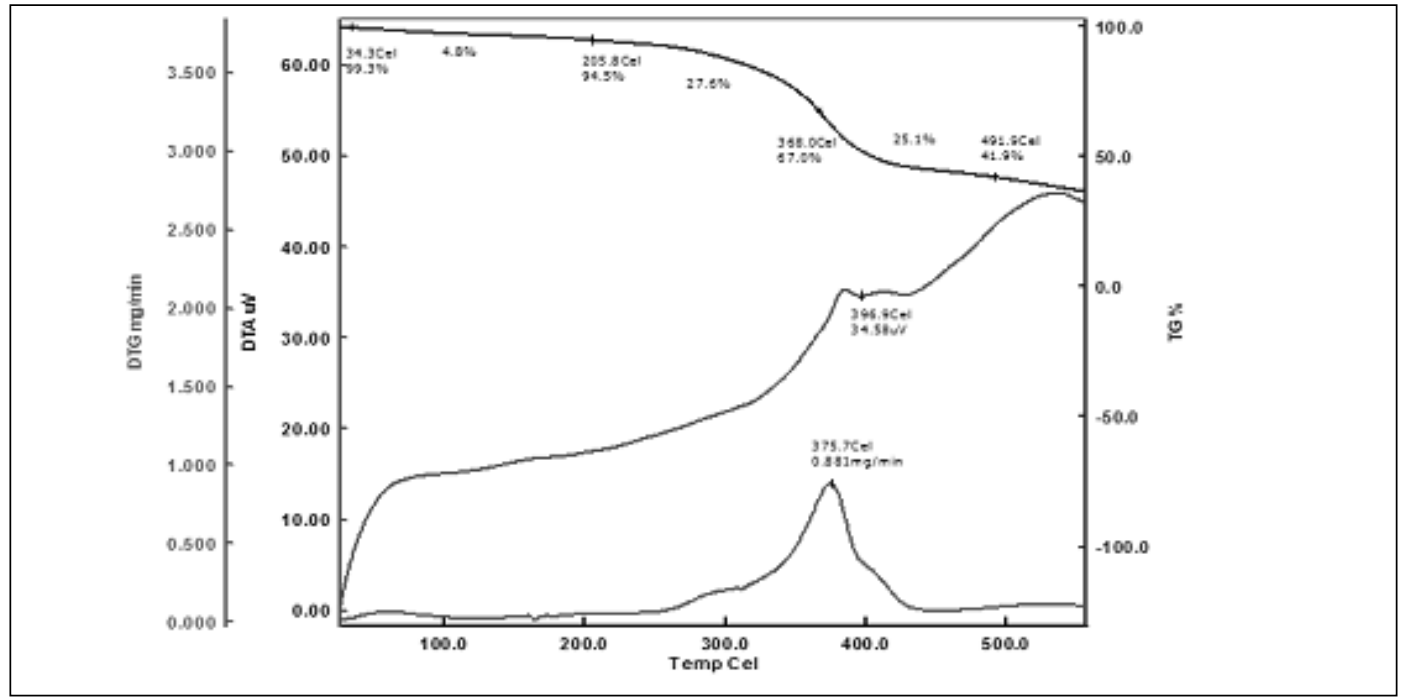

Fig. 6. TG, DTG and DTA of Composite C3 (=JGJGJ) 


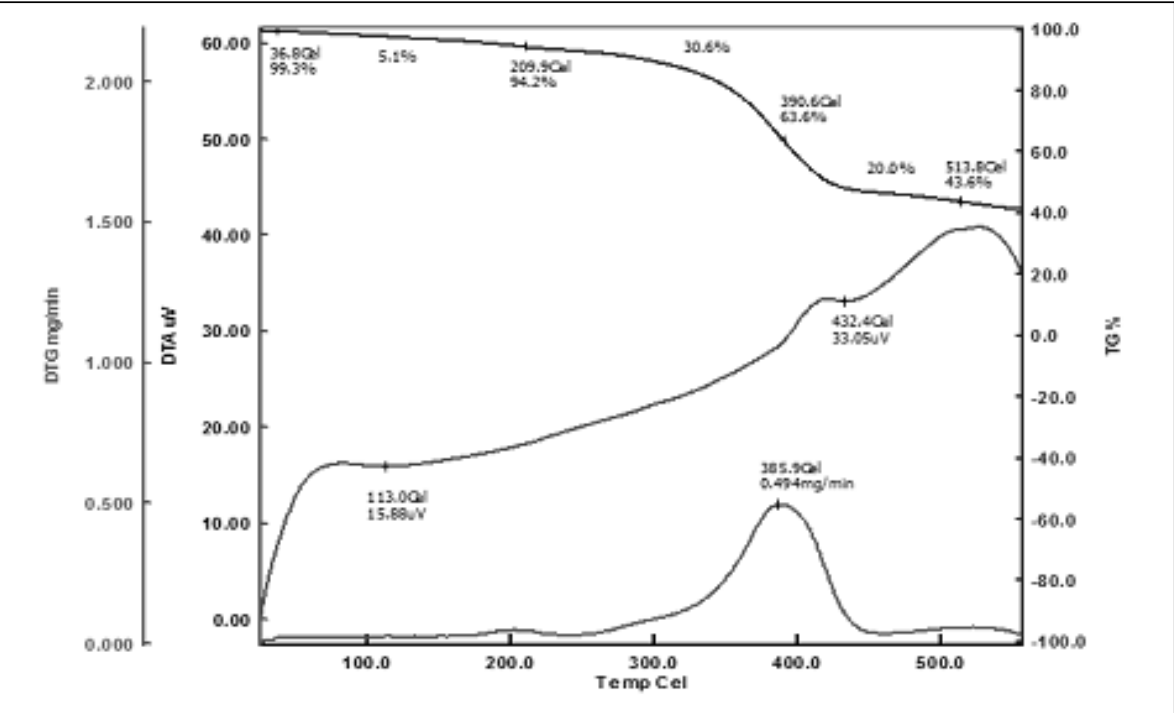

Fig. 7. TG, DTG and DTA of Composite C4 (=GJGJG)

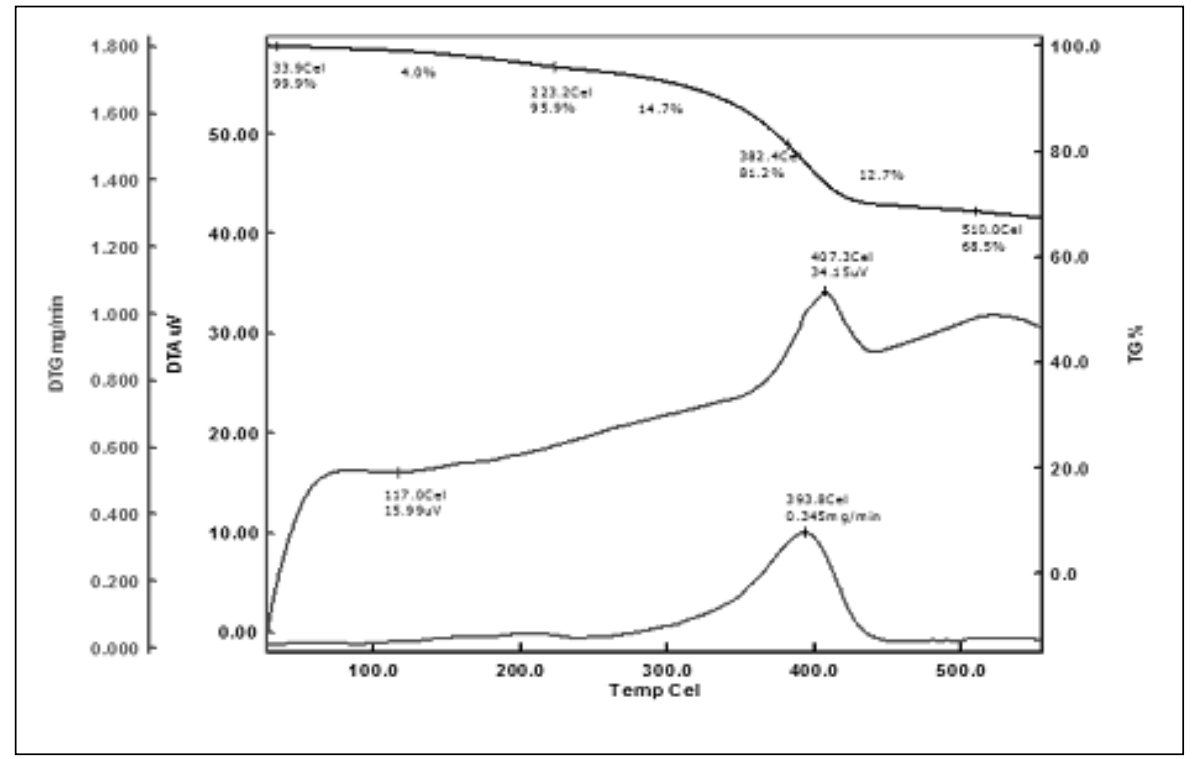

Fig. 8. TG, DTG and DTA of Composite C6 (=GGGGG)

the hardness increases with the increase in glass content in the composite. Glass fiber makes the composite more resistant to plastic deformation as micro hardness increases with the increase of glass content in the composite.

TGA, DTG and DTA curves of the composites are given on the Figures 5-8. TG curves (Figures 5-8) show that the composites loss their $50 \%$ weight at temperatures $379.6^{\circ} \mathrm{C}$, $405.71^{\circ} \mathrm{C}, 423.02^{\circ} \mathrm{C}$, for $\mathrm{C} 1, \mathrm{C} 3$, and $\mathrm{C} 4$ respectively. But when the composite consisting of all glass fibers TG curve shows that composite degrades up to $67.34 \%$ of its weight as more high temperature is needed to fully degrade glass fibers. It can be concluded that the composites are all ther mally stable. The thermal stability increases as the glass fiber content increases in the composites.

\section{Conclusion}

From the experimental study on physical and mechanical behavior of jute and glass fiber reinforced polyester based hybrid composites it can be concluded that optimum incorporation of synthetic fiber with natural fiber increases overall strength of the hybrid composite. Such as the fiber loading and orientation significantly influences the different properties of composites. The maximum tensile strength was obtained for the composite ' $\mathrm{C} 4$ ' of all other hybrid compos- 
ites having glass fiber on the external layer. On the other hand tensile strength of composite which contains one extra glass layer and one layer less jute fiber had shown less tensile strength than the composite ' $\mathrm{C} 4$ '. Flexural strength results of the composites show that composite $\mathrm{C} 4$ have the high flexural strength than the other hybrid composites. The water absorption rate was higher in the composite having high jute fiber content than glass fiber. Micro hardness test revealed an increase in hardness property of the composites as the synthetic fiber content was increased. Thermal analysis show that the composite having glass fiber content higher in ratio than jute fiber is more stable thermally. The results indicate that in this research work the optimum composition of fibers in the composite was three layers of glass fiber and two layers of jute fiber.

\section{Acknowledgement}

The authors acknowledge the technical support provided by Pilot Plant and Process Development Centre of Bangladesh Council of Scientific and Industrial Research (BCSIR), Bangladesh.

\section{References}

Bindal A, Singh S, Batra NK and Khanna R (2013), Development of glass/jute fibers reinforced polyester composite, Indian Journal of Material Science 2013: 1-6.

Bleat SM and Humberstone L (1999), Mechanical and electrical assessment of hybrid composites containing hollow glass reinforcement, Composites Science and Technology 59 (9):1321-1329.

Chandra R, Singh SP and Gupta K (1999), Damping studies in fiber-reinforced composites- a review, Composite Structures 46(1): 41-51.

Davim JP, Reis P and Antonio CC (2014), Experimental study of drilling glass fiber reinforced plastics (GFRP) manufactured by hand lay-up, Composites Science and Technology 64(2): 289-297.

Dalbehera S and Acharya S K (2014), Study on mechanical properties of natural fiber reinforced woven jute-glass hybrid epoxy composites, Advances in polymer science and technology: an international journal 4(1): 1-6.

Deshpande S and Rangaswamy T (2014), Effect of fillers on E-glass/jute fiber reinforced epoxy composites, International journal of engineering research and applications (IJERA) 4 (8): 118-123.

Dhal JP and Mishra SC (2013), Processing and properties of natural fiber reinforced polymer composite, Journal of Materials 2013: 1-6.

Hossan MJ, Gafur MA, Karim MM and Rana AA (2015), Mechanical properties of Gelatin-Hydroxyapatite composite for bone tissue engineering, Bangladesh J. Sci. Ind. Res. 50 (1): 15-20.

Haldar AK, Singh S and Prince P (2011), Vibration characteristics of thermoplastic composite, in Proceedings of AIP conference, Jaipur, India.

Kusmono and Ishak ZAM (2013), Effect of clay addition on mechanical properties of unsaturated polyester/glass fiber composites, International journal of polymer science (2013):1-7.

Muthuvel M, Ranganath G, Janarthanan K, and Srinivasan K (2013), Characterization study of jute and glass fiber reinforced hybrid composite material, International journal of engineering research \& technology (IJERT) 2 (4): 335-344.

Srivastava A and Choudhary S (2013), Design and structural analysis of jute/E-glass woven fiber reinforced epoxy based hybrid composite leaf spring under static loading, International journal of mechanical engineering and research 3 (6): 573-582.

Singh S, Kumar P and Jain SK (2012), An experimental and numerical investigation of mechanical properties of glass fiber reinforced polyester composites, Advanced Materials Letters 4 (7): 567-572.

Uddin N and Kalyankar RR (2011), Manufacturing and structural feasibility of natural fiber reinforced polymeric structural insulated panels for panelized construction, International journal of polymer science (2011): 1-7.

Velu S and Srinivasan R (2015), Glass-jute fiber reinforced epoxy composites, International journal of science and research (IJSR) 4(4): 1714-1717.

Venkateshwaran N, Elayeperumal A and Sathiya G K (2004), Prediction of tensile properties of hybrid-natural fiber composites, Composites B43 (2):289-297.

Received: 30 September 2015; Revised: 26 November 2015; Accepted: 31 January 2016. 